\begin{tabular}{lr}
\hline UPT BAHASA \\
UNIVRSIAS TANUNGPURA
\end{tabular}

\title{
A Library Research: Teaching English to English Language Learners with Learning Disabilities
}

\author{
Siti Dwi Karmila ${ }^{1}$ and Jamie Harrison ${ }^{2}$ \\ SMPN 1, Pontianak - Indonesia ${ }^{1}$; Teaching English for Speakers of Other Language, Auburn University - USA ${ }^{2}$ \\ Lubnaqisthy1527@gmail.com
}

\begin{abstract}
Lack of knowledge about learning disability makes the English teachers in developing non-English speaking countries hardly distinguish the presence of students with learning disability among their students in their general classroom setting. Then, when they are able to identify their students having learning disabilities, other problems come up since the schools do not have enough resources and special education services. It is so problematic since they cannot send these students to special education school as learning disability (LD) is still considered mild for admission into this type of school. The aim of this research, thus, is to provide some strategies or methods to teach English to English language learners (ELLs) both with LD and without LD in general setting classroom. There were 20 and more empirical research articles about appropriate strategies to teach English to ELLs with or without LD collected for discussing this issue. The result of this paper is a set of collected appropriate strategies to teach English language learners (ELLs) with and/or without learning disability (LD) in general classroom setting such as SIOP Model, Instructional Scaffolding, Comprehensible Support Input, and Differentiated Instruction.
\end{abstract}

\section{Keywords}

LD, ELLs, ELLs with LD, Special Education.

\section{INTRODUCTION}

Learning disabilities are still not common in developing non-English speaking countries so that teachers hardly identify the existences in their classroom. Let alone, there is no typical manifestation of students with learning disabilities (Turnbull, Turnbull, Wehmeyer, Shogren, 2013). Insufficient knowledge of the English teachers in non-English-speaking countries about students with learning disabilities makes it harder to identify students with learning disabilities among their peers. As a result, teachers may not be able to accommodate the students with learning disabilities. Consequently, lessons are often misunderstood by students with learning disabilities.

Moreover, learning disability identification is more complicated in the English classroom in non-English speaking countries. Teachers often regard the students' imperfect ability in English skills because English is their foreign language. Teachers, who do not understand that they probably have both students with learning disabilities and students without learning disabilities, might have inappropriate expectation that results in inappropriate referrals to special education. They will probably try to share information in a language that ELLs with LD may not comprehend and can end up to be a failure to provide students with the necessary supports to acquire new content knowledge in English (The IRIS Center, 2011)

Based on the issue mentioned before, it is crucial for the English teachers in non-English speaking countries to increase their awareness of the presence of the students with learning disabilities in general classroom setting. Being aware of it will assist the English teachers in nonEnglish speaking countries to apply teaching accommodation which is appropriate for not only English language learners with learning disabilities but also English language learners without learning disabilities in their classrooms in general setting school.

This research, therefore, purposefully provides some information that can 
accommodate the English teachers in nonEnglish speaking countries to identify manually and to teach applicably ELLs with LD in general classroom setting.

\section{METHODOLOGY}

This library-based research reviewed some studies, research, or literature that address to the definition of ELLs with LD, the ways to identify ELLs with LD and the appropriate techniques for teaching English to ELLs with or/and without LD in general setting classroom in non-English-Speaking countries. There were 20 more empirical research articles from 2005 to 2017 collected through computer searches of the database and through book readings. The articles were analyzed and synthesized in order to make connections among the theories. Also, consulting with the experts in the teaching English for the speakers of other languages (TESOL) and in Special Education was done as well for the experts' individual and collective insight.

\section{FINDING AND DISCUSSION}

\subsection{ELLs with Learning Disabilities}

The term English Language Learners (ELLs) refers to the learners whose native languages are the languages other than English that might impact the learners' English language proficiency (Garcia et al., 2008; The IRIS Center, 2011). ELLs usually have difficulties in speaking, reading, writing and understanding the English language (Turnbull, Turnbull, Wehmeyer, Shogren, 2013). The difficulties that ELLs have are nearly similar to the difficulties that students with learning disability (LD) have. According to IDEA - Individual with Disabilities Education Act - (as cited in Turnbull, Turnbull, Wehmeyer, Shogren, 2013), a specific learning disability is a disorder in one or more of the basic psychological processes involved in understanding or in using language, spoken or written which is manifested in an imperfect ability to listen, think, speak, read, write, spell or do mathematical calculations (p.106). Both ELLs and students with LD have difficulties in using language; however, one thing that should be highlighted that students with LD have obstacle to use not only the foreign/second language but also their native language. Therefore, the ELLs with LD are ELLs who have a disorder of basic psychological processes that hinders them to use both their native language and foreign language, either spoken or written, properly.

Since LD in ELLs is barely concealed, English teachers in non-English speaking countries, developing ones in particular, might hardly recognize that their students have learning disability as they seem simply not understand English as their second/foreign language. Yet, English teachers in non-English speaking countries should be aware the possibility of LD existence among their ELLs. They should be able to identify, at least manually, their ELLs with LD in order to accommodate this type of students.

\subsection{The Characteristics of English Language Learners with Learning Disabilities}

It may be more challenging to identify ELLs with LD in developing non-English speaking countries which lack of resources, information or experts in special education. However, English teachers can collaborate with other teachers, like the first language teachers, to identify them. The teachers can also observe the students by the characteristics that the students show in the classroom. Spear-Swerling (2006) states some characteristics of the ELLs with learning disabilities: (a) the ELL has a history of oral language delay or disability in the native language; (b) the ELL has had difficulty developing literacy skills in the native language (assuming adequate instruction in the native language); (c) there is a family history of reading difficulties in parents, siblings, or other close relatives (again, assuming adequate opportunity to learn to read); (d) the ELL has specific language weaknesses, such as poor phonemic awareness, in the native language as well as in English; and (e) the ELL has had researchbased, high-quality reading intervention designed for English language learners, and still is not making adequate progress relative to other, similar English language learners.

Moreover, to know the distinctions between the students with learning disabilities and English Language learners can help teachers to avoid the misidentification. Spear-Swerling (2006) explains that students with learning disabilities have difficulties in reading and/or writing inconceivably due to the problems in phonological processing which significantly influence the ability to identify letters, words, or sentences. Meanwhile, ELLs do not have difficulties in reading and/or writing in their native language, but they can show poor proficiency in both reading and writing in English which adversely influences their development of English literacy.

Navarette and Watson (2013) add that it is very common for ELLs to have more developed skills in English vocabulary, pronunciation, grammar and comprehension than students whose first language is English. Yet, students with learning disabilities experience errors or limited skills in vocabulary, pronunciation, grammar and have no comprehension when they communicate in their first language. In 
the same way, students with LD tend to have impairment in interactions with their family members and others who speak the same darn language; meanwhile, ELLs have less opportunity to use English which affects their proficiency status in using English to communicate. (p.3)

From those three articles reviewed above, all of them emphasized that ELLs do not have poor proficiency in speaking, writing, reading and listening in their first or native language. However, if ELLs with LD have problems in phonological processing that impacts their proficiency in speaking, writing, reading and listening in both their first or native language and English.

\subsection{Teaching English to English Language Learners with Learning Disabilities}

In developed countries, like the United States, the ELLs or ESL students are protected by education laws. U.S. Department of Education (2015) states that ELLs with learning disabilities must be provided both the language assistance and disability-related services to which they are entitled under federal law. The proposition from U.S. Department of Education is sufficiently ideal for ELLs with learning disabilities. It probably can be applied in developed countries like the United States where most public schools have good resources and special education services. These ideal circumstances may be quite hard to be built in developing countries, like Indonesia. Many English teachers in the developing countries which English is still foreign language are barely able to identify their students having learning problems. Even though they are able to identify their students having learning problems, the schools might not have enough resources and special education services. It is so problematic since they cannot send these students to special education school as learning problem is still considered mild to attend there. Therefore, the teachers need to find an effective strategy that can be applied to either students with LD or students without LD. These strategies should meet some criteria that John Carr (2012) states: (a) the strategy should not be entirely new so that teachers don't feel overloaded; (b) the strategy has to be relatively easy to learn to keep time and professional development costs down; (c) the strategy should be able to be used frequently, if not daily; and (d) the set of strategies should be interdependent (i.e., one strategy can facilitate the use of another one).

Concerning to the criteria that John Carr states, there are some effective strategies that can be applied to teach English for the students with/out learning disabilities. SIOP Model, scaffoldings, comprehensible input support, and differentiated instruction are some strategies that fit the criteria of effective strategies according to John Carr (2012).

\section{SIOP Model}

Sheltered Instruction Observation Protocol Model (SIOP Model) is an approach for teaching content to English learners (ESL/EFL learners) in strategic ways that the subject matter concepts comprehensible while promoting the students' English Language development (Echevarria, Vogt, \& Short, 2008). Echevarria, Vogt, and Short add that SIOP model can be the best-suited interaction used to teach content area subject, included English lesson, for English language learners with or without learning disabilities. Echevarria (1998) presents a study that illustrates middle school students with learning disabilities made significant progress in four domains of language, specifically in the areas of language production when teachers used SIOP model (as cited in Echevarria, Vogt, \& Short, 2008). Moreover, Echevarria and Graves (2007) states that both English language learners and students with LD necessitate accommodation in learning English and the components and features of SIOP Models are the best suited for those two kinds of students.

Some features in SIOP models (short, 2008) help the teachers be able to teach ELLs with LD effectively because by implementing it, the teachers also do the effective instructional strategies for ELLs with LD. The effective instructional strategies that SIOP Model provides are to provide visual or graphic organizer, incorporate models, demonstration or role plays in their teaching, to use teacher presentation cues to emphasize key points, to do the scaffoldings to introduce the key concepts, to involve student-student interaction by implementing every learner response techniques, practice in context of daily activities, to point out the benefit of using learning strategies, and to explain specifically what students will be able to accomplish once they know the skill (Turnbull, Turnbull, Wehmeyer, Shogren, 2013).

\section{Instructional Scaffoldings}

One of the effective instructional strategies for Students with LD is to do the scaffolding to introduce the key concepts. Instructional scaffolding is "a process through which a teacher adds supports for students in order to enhance learning and aid in the mastery of tasks" (The IRIS Center, 2005, p.1). It is fluid, dynamic, interactive, adjustable, and temporary process which can be decreased or increased depending on the students' progress and is applied to help the students make cognitive connections (Santamaria, Fletcher, \& Bos, 2002 as 
cited in Nguyen, 2012; The IRIS Center, 2005). Scaffolding is associated with the substantial amounts of support and assistance in the earliest stages of teaching in order to facilitate the student to more understand a new concept or strategy (Vygotsky, 1978; Vacca, 2002; Echevarria et al., 2008); furthermore, the teachers can decrease or increase the amounts of scaffolding, depending on the learners' proficiencies (Vacca, 2002 as cited in Echevarria et al., 2008). Scaffolding is differentiated into two types of scaffolding; verbal scaffolding and procedural scaffolding.

Verbal scaffolding is a process through which the teachers apply prompting, questioning, and elaboration to aid the students to move on the higher levels of language proficiency, comprehension, and thinking (Echevarria, Vogt \& Short, 2008).

Procedural scaffolding includes some supports that make teaching learning process effective (Echevarria, Vogt \& Short, 2008). The supports include the following (p.101):

1) Using an instructional framework that includes explicit teaching, modeling and practice opportunities with others, and expectations for the independent application.

2) One-on-one teaching, coaching, and modeling

3) Small group instruction with children practicing a newly learned strategy with another more experienced student

4) Partnering or grouping students for reading activities, with more experienced readers assisting those with less experience (Nagel, 2001 as cited in Echevarria, Vogt \& Short, 2008)

There are some ways to implement scaffoldings to ELLs with LD. One of those is Modeling. The teachers can model or demonstrate each step in the task or strategy multiple times so the students can fully understand the new task or strategy. It is also important for the teachers to do the repetition in order to allow the students to know how to perform each step and why each step is important (The IRIS Center, 2005). Another implementation is practicing. The students should have a chance, either individually or as a group, to practice the task or the strategy with the teachers (p.2). The other implementation is creating graphic organizers. Graphic organizers can be used "as a prereading tool to prepare students for the content of a textbook chapter. The organizer can also be used to illustrate a chapter's text structure, such as comparative or chronological" (Vost \& Echevarria, 2008 as cited in Echevarria et al., 2008, p. 101 - 102).

\section{Comprehensible Support Input}

Comprehensible input support is referred to the technique that teachers create to make the message understandable for students (Krashen, 1985 as cited in Echevarria, Vogt, \& Short, 2008). It is important to apply comprehensible input support to help ELLs understand the lesson or concept that the teachers taught,and this support should be evident throughout the lesson (Echevarria,Vogt, \& Short, 2008). To be successful in applying for comprehensible input support, the teachers need to concern the uniqueness of the ELLs' linguistic need and consistently apply it into their daily teaching routines (p.79).

Leonard Baca, Director of the BUENO Center for Multicultural Education, points out in IRIS modules (Teaching English Language Learners: Effective Instructional Practices Retrieved, 2011) about the importance of comprehensible input in the teaching learning process of English language. He adds that this comprehensible input applied not only to the oral aspects but to the reading as well as the writing part of it. Comprehensible input support which teachers provide can help the teachers know how to distinguish students' potential linguistic difficulty and subsequently by monitoring their speech, modeling what they want the students to do and using a variety of modalities in their instruction (The IRIS Center, 2011).

\section{Differentiated Instruction}

The idea of Differentiated Instruction was born because every student has their own learning style and the teachers are expected to be able to accommodate their learning styles. Differentiated Instruction is an evidence-based framework used by teachers to apply various strategies in adjusting their curriculum and instruction in order to achieve optimal learning result for all students: average learners, English language learners, struggling students, students with learning disabilities, and gifted and talented students (The IRIS Center, 2010). The purpose of this strategy framework is to reach the best out of each student (Weselby, 2014).

In doing Differentiated Instruction, it is important for the teachers to get to know their students when they apply Differentiate Instruction. The teachers need to know their students' readiness, interest and learning style in order to figure out their students' needs (The IRIS Center, 2010). Another thing that the teachers need to concern in doing differentiated instruction is its instructional elements. There are three main instructional elements: content, process, and product (The IRIS Center, 2010; Weselby, 2014). Content is the knowledge and skills that students need to master; the process is the activities that students do to master the content; the product is the method that students apply to demonstrate learning (The IRIS Center, 2010). 
According to the IRIS Center (2010), the teachers who apply Differentiated Instruction usually, practice various instructional approaches and alter assignments to meet the needs of the students. To figure out the students' needs, the teacher should do assessment towards the students in order to determine their readiness levels. Based on the students' readiness levels, the teachers can adjust the instruction as needed. They would better prepare various options for students to learn and demonstrate their knowledge and make an effort to create engaging and meaningful. The application of different grouping formats and flexible grouping is also important to do to best reach each student (p.1). While the teachers implement Differentiated Instruction, they actually implement proper instruction to teach ELLs with LD unconsciously. As they figure out that there are students with LD among their students, they will adjust the instruction as what students with LD need.

\section{CONCLUSION}

The developed countries, like Europen countries and America, have already developed a special education program in their schools. They also have resources and special education teachers that can overcome the issue of special education. On the other hand, in most developing countries, special education is still uncommon to discuss. They do not have enough resources and special education teachers. However, they still can anticipate the possibility of the existence of the students with learning disabilities in their class.

First of all, teachers need to identify ELLs with LD. The English teachers in developing nonEnglish-speaking countries might find it difficult to do the identification through a scientific intervention because of the lack of resources, knowledge, and experts. Yet, they still can do the manual simple identification. They can collaborate with the teachers who teach the native language in the school because the students who possibly have a learning disability can be detected if they have experienced an error or limited skills in vocabulary, pronunciation, grammar and comprehension when they communicate in their first language.

After the English teachers find out that they have ELLs with LD, they need to decide the proper techniques or approaches which fit for teaching not only ELLs with LD but also ELLs without LD. There are some possible effective approaches that can help English teachers who lack of resources and have no special education services to teach ELLs with or without LD altogether. First strategy is SIOP Model or Sheltered Instruction Observation Protocol Model. It is an approach for teaching content to English learners (ESL/EFL learners) in strategic ways that the subject matter concepts

\begin{tabular}{l|l|l|}
\hline$I S S N$ 2657-1617 & 40
\end{tabular}

comprehensible while promoting the students' English Language development (Echevarria, Vogt, \& Short, 2008). Echevarria, Vogt, and Short add that SIOP model can be the best-suited interaction used to teach content area subject, included English lesson, for English language learners with or without learning disabilities. Moreover, Echevarria and Graves (2007) states that both English language learners and students with LD necessitate accommodation in learning English and the components and features of SIOP Models are the best suited for those two kinds of students.

The second strategy is instructional scaffolding is "a process through which a teacher adds supports for students in order to enhance learning and aid in the mastery of tasks" (The IRIS Center, 2005, p.1). To implement the instructional scaffoldings to ELLs with LD, the teachers can do the modeling, repetition, practicing and applying graphic organizers to make the ELLs with LD fully understand the lesson.

Next strategy is comprehensible input support. Comprehensible input support is referred to the technique that teachers create to make the message understandable for students (Krashen, 1985 as cited in Echevarria, Vogt, \& Short, 2008). It is important to apply comprehensible input support to help ELLs understand the lesson or concept that the teachers taught,and this support should be evident throughout the lesson (Echevarria,Vogt, \& Short, 2008). Teachers can do some features of comprehensible input support like speech appropriate for students' proficiency levels, clear explanation of academic tasks, and a variety of techniques used to make content concepts clear (Echevarria, Vogt, \& Short, 2008; The IRIS Center, 2011) when they teach English to ELLs with LD.

Then, the last possible strategy is differentiated Instruction is an evidence-based framework used by teachers to apply various strategies in adjusting their curriculum and instruction in order to achieve optimal learning result for all students: average learners, English language learners, struggling students, students with learning disabilities, and gifted and talented students (The IRIS Center, 2010). The purpose of this strategy framework is to reach the best out of each student (Weselby, 2014

Learning disability is a disability which is barely noticed by the teachers. Especially in developing countries, learning disability is considered as a mild disability which does not need to have great attention to the educators or teachers. Unconsciously, the educators' and teachers' negligence towards them makes them be taught inappropriately. Their learning needs are not accommodated. As the result, they tend to be labeled the failed students. We should feel more responsible 
for our students. We need to assess our students either manually or scientifically. We also need to apply the fitting approaches, methods, or strategies of teaching in order to accommodate all of our students. The aim of this library research is to provide knowledge and solution to the English teachers in developing non-English speaking countries about learning disability. It is hoped that with the understanding of learning disability, the English teachers can increase the English proficiency of either students with learning disabilities or students without learning disabilities. Also, this paper should be able to contribute to future research on similar topics.

\section{REFERENCES}

Binghamton University Libraries. (2017). How to do library research. Retrieved from http://libraryguides.binghamton.edu/libraryresea rch

Daniel, S.M., \& Conlin, L. (2015). Shifting attention back to ents within the Sheltered Instruction Observation Protocol. Tesol Quarterly, 49, 169187. doi: 10.1002/tesq. 213

Disability Fact Sheet \#7. (2008). Learning disabilities [fact sheet]. Retrieved from http://www.Parentcenterhub.Org/wpcontent/uploads/repo_items/fs7.Pdf

Echevarria, J., Vogt, M., \& Short, D.J. (2007). Making content comprehensible for English learners: The SIOP Model (3 ${ }^{\text {rd }}$ ed.). Boston: Pearson, Allyn and Bacon

Elmer E. Rasmuson Library. (2016). Library Research Process. Retrieved from https://library.uaf.edu

Ena, O. (2013). Visual analysis of e-textbook for senior high school in Indonesia. (Doctoral dissertation). Retrieved from http://ecommons.Luc.Edu/luc_diss/513

Garcia, O., Kleifgen, J.A., \& Falchi, L. (2008). From English language learners to emergent bilinguals. Equity Matters: Research review, 1. Retrieved

from http://www.Equitycampaign.Org/i/a/document/6 468_ofelia_ell_final.Pdf

Carr, J. (2012). Strategies for teaching English learners and students with Learning disabilities. ASCD Express, 8. Retrieved from www.ascd.org/ascdexpress.

Klinger, J. (2015). Distinguishing language acquisition from learning disabilities. Retrieved from

http://schools.Nyc.Gov/NR/rdonlyres/DABEF5 5A-D155-43E1-B6CB-

B689FBC9803A/0/languageacquisitionjanettekl ingnerbrief_73015.Pdf
Navarette, L., \& Watson, S. M. R. (2013). English language learners: The impact of language and socio-cultural factors on learning. Retrieved from www.council-for-learning-disabilitiesorg/wp-context/uploads/2013/11/CLD-

Infosheet-Diversity-2013.pdf.

Short, D. (2013). Training and Sustaining Effective Teachers of Sheltered Instruction. Theory into practice, $\quad 52, \quad 118-127 . \quad$ doi: 10.1080/00405841.2013.770329

Spear-Swerling, L. (2006). Learning disabilities in English language learners. Retrieved from http://www.Ldonline.Org/spearswerling/learnin g_disabilities_in_english_language_learners

The IRIS Center. (2005). Providing instructional supports: Facilitating mastery of new skills. Retrieved from http://iris.peabody.vanderbilt.edu/module/sca/

The IRIS Center. (2009). Cultural and linguistic differences: What teachers should know. Retrieved from http://iris.peabody.vanderbilt.edu/module/clde

The IRIS Center. (2010). Differentiated Instruction: Maximizing the Learning of All Students Retrieved on [month, day, year] from http://iris.peabody.vanderbilt.edu/module/ di/

The IRIS Center. (2011). Teaching English Language Learners: Effective Instructional Practices Retrieved from http://iris.peabody.vanderbilt.edu/module/ell/

The speaking English world. (2008). [Interactive maps illustrating the expansion of English use in the world, 2008]. Middle English and modern English. Retrieved from https://courses.Nus.Edu.Sg/course/elltankw/hist ory/me.Htm

Turnbull, A., Turnbull, R., Wehmeyer, M.L., \& Shogren, K.A. (2013). Understanding students with learning disabilities. In A. Turnbull, R. Turnbull, M.L. Wehmeyer, \& K. Shogren (eds.), Exceptional lives: special education in today's schools (p. 106). New Jersey: Pearson.

U.S. Department of education. (2015). Ensuring English learner students can participate meaningfully and equally in educational programs [facts sheet]. Retrieved from http://www2.Ed.Gov/about/offices/list/ocr/docs/ dcl-factsheet-elstudents-201501.Pdf

Weselby, C. (2014, October 1). What is Differentiated Instruction? Examples of how to differentiate instruction in the classroom. Retrieved from http://education.cuportland.edu/blog/teaching-strategies/examplesof-differentiated-instruction/ 
